trends. Furthermore, such information would help contribute to relevant research in mental health service provision to Black and minority ethnic groups in the UK.

1 Office for National Statistics. 2001 Census. ONS 2001

2 Wright S, Bindman J, Thornicroft G, Butcher M. Thematic Review of NHS Funded Mental Health Research in Relation to the National Service Framework for Mental Health. Institute of Psychiatry, 2000

3 National Institute for Health and Clinical Excellence. Schizophrenia - Atypical Antipsychotics (TA043). NICE, 2002

4 Sashidharan SP. Inside Outside: Improving Mental Health Services for Black and Minority Ethnic Communities in England. Department of Health 2003

*Aqeel Hashmi Consultant Psychiatrist, University of Sharjah, College of Medicine, PO Box 24713, Sharjah, UAE, email: aqeelhashmi@minddoctor. org, Ayesha Rahim Specialty Registrar year 4, Greater Manchester West Trust, UK, M. Shahbaz Sharif SpecialtyTrainee year 2, Eastern Deanery, Peterborough, UK

doi: $10.1192 / p b .33 .8 .313 a$

\section{Educational factors associated with e-learning}

In her excellent editorial, Elizabeth E. Hare discusses e-learning for psychiatrists. ${ }^{1}$ We wish to highlight another e-learning resource for psychiatrists, of which the readership may not be aware.

Mayes et al suggest that 'there are really no models of e-learning per se only e-enhancements of models of learning.'2 So as with all learning, e-learning needs to be based on good pedagogical principles, with good instructional design as a foundation.

Further, Hattie conducted a metaanalysis where he examined the relative effectiveness of various educational factors on student achievement. ${ }^{3}$ The top seven in terms of effect size were: reinforcement (1.13), student's prior cognitive ability (1.00), instructional quality (1.04), direct instruction (0.82), remediation/feedback (0.65), student's disposition to learn (0.61) and class environment (0.56)

It is possible to see how e-learning may enhance 'reinforcement' and 'student's disposition to learn'. Video e-learning represents another form of e-learning, which also addresses the 'direct instruction' and 'class environment' interventions - it may be easier to learn from a 'live' teacher talking with credibility and passion directly to the student in a classroom, rather than reading the same words from written text. By way of example, the Video Journal of Psychiatry is a sponsored online service providing classroom-like lectures on MRCPsych curricula and continuing professional development topics to Irish psychiatrists (www.vjpsych.ie)

Cook et al have shown that internetbased learning is beneficial to students and is probably as effective as the traditional instructional methods. ${ }^{4}$ What is needed now is more research, comparing the efficacy of the various internet-based interventions.

1 Hare EE. E-learning for psychiatrists. Psychiatr Bull 2009; 33: 81-3.

2 MayesT, de Freitas S. JISC e-Learning Models desk study Stage 2: Review of e-learning theories, frameworks and models. Joint Information Systems Committee, 2004.

3 HattieJ. Influences on Student Learning (inaugural lecture). University of Auckland, 1999 (http:// www education auckland ac nz/webdav/site/ education/shared/hattie/docs/influences-onstudent-learning.pdf)

4 Cook DA, Levinson AJ, Garside S, Dupras DM Erwin PJ, MontoriVM. Internet-based learning in the health professions: a meta-analysis. JAMA 2008; 300: 1181-96.

*Pauline M. Devitt Senior Registrar in Psychiatry, Coolock Mental Health Services, Coolock Health Centre, Cromcastle Road, Dublin, email: paulinedevitt @eircom.net, Elissa Dooley Registrar, Coolock Mental Health Services, Dublin

doi: 10.1192/pb.33.8.314

\section{General practitioners and early intervention in psychosis}

Delay in the initiation of treatment in individuals with first-episode psychosis has been associated with poorer longterm outcomes. ${ }^{1}$ El-Adl et al report on general practitioner (GP) experiences of patients with a first psychotic episode. ${ }^{2}$ However, I have a number of concerns about the reported results.

The low reported incidence of new cases per year within the authors' locality ( $n=100)$ was demonstrated by the majority (68\%) of GPs seeing only one or two such individuals per year. I find it difficult to see, given these low cell counts, how GPs could answer questions about initiating treatment (10\%, 25\%, $50 \%$ and $75 \%$ of the time) and thus conclude that GPs are unlikely to start treatment before referring to secondary care services.

The information requested from the GPs regarding engagement of patients with first-episode psychosis and causes of delayed referral are based on these low patient numbers and would be subject to recall bias on behalf of the GP. Getting the patients' views on barriers to mental health services would certainly have helped triangulate the data.

I was also concerned that the data published were 5 years old and as such the current generalisability of these results could be questioned.

With the National Institute for Health and Clinical Excellence schizophrenia guidelines recently updated ${ }^{3}$ and early intervention/crisis resolution teams the norm rather than exception, El-Adl et al echo the view that active engagement with our primary care colleagues is paramount in ensuring these patients receive both a responsive and effective service.

1 BarnesTRE, Leeson VC, Mutsatsa SH, Watt HC, Hutton SB, Joyce EM. Duration of untreated psychosis and social function: 1-year follow-up study of first-episode schizophrenia. $\mathrm{Br} J$ Psychiatry 2008; 193: 203-9.

2 El-Adl M, BurkeJ, Little K. First-episode psychosis: primary care experience and implications for service development. Psychiatr Bull 2009; 33 $165-8$

3 National Institute for Health and Clinical Excellence. Schizophrenia: Core Interventions in theTreatment and Management of Schizophrenia in Adults in Primary and Secondary Care (update), CG82. NICE, 2009

Alexis Bowers Specialist Registrar, Central and North West London NHS Foundation Trust, Park Royal Centre for Mental Health, London NW10 7NS, email: dralexisbowers@hotmail.com

doi: 10.1192/pb.33.8.314a

\section{General practitioners and early intervention in psychosis: reply}

We wish to express our thanks to Dr Bowers for the interest in our article. ${ }^{1}$ Dr Bowers feels that the majority of GPs reporting seeing only one or two patients with first-episode psychosis a year is a low figure. However, this agreed with Shiers \& Lister's findings. ${ }^{2}$

Dr Bowers expressed reservations about the GPs' ability to answer questions about their prescribing trends to patients with first-episode psychosis. I may disagree with this view as the low number of patients does not exclude or make it difficult for GPs to comment on engagement or otherwise. It is our view that clinicians, including GPs, may be more able to remember cases that are not very frequently seen than common ones.

Dr Bowers' suggestion that getting the patients' views on barriers to mental health services would certainly have helped to triangulate the data - this puts forward the idea for another study. The scope of this study was about GPs' experience and not patients' or carers' experience. 
Finally, Dr Bowers expressed his concern about the length of time elapsed between conducting our study and the results being published. We appreciate the importance of avoiding such delay but would point out the following: (1) clinicians with numerous clinical duties need to plan the study, make the time for data analysis, writing and submitting papers, responding to reviewers, and wait after putting the paper in the queue of the articles accepted for publication until it is published; (2) the real question should be whether or not this delay has any impact on applicability of the study results. We feel that where the early intervention service model has already been adopted it is not too late for it to be reviewed and further developed. If, on the other hand, some areas have not yet developed their early intervention model, it is not at all late.

1 EL-Adl M, BurkeJ, Little K. Frist-episode psychosis: primary care experience and implications for service development. Psychiatr Bull 2009; 33: 165-8.

2 Shiers $D$, Lester $H$. Early intervention for firstepisode psychosis needs greater involvement of primary care professionals for its success. BMJ 2004; 328: 1451-2.

*Mamdouh EL-Adl Consultant Psychiatrist Northamptonshire Healthcare NHS Trust, Campbell House, Campbell Square, Northampton NN1 3EB, email: mamdouhkandil@doctors.org.uk, John Burke Consultant Psychiatrist, Northamptonshire Healthcare NHS Trust, Karen Little Clinical Governance and Professional Development Manager, Preston Primary Care Trust

doi: 10.1192/pb.33.8.314b

\section{Doctors in the house. Home visits for older people: a practical model outside Yorkshire}

There is a curious sentence in Negi et al's paper about psychiatric out-patient clinics for older adults. ${ }^{1}$ When they refer to Benbow's paper about community clinics, ${ }^{2}$ they state that 'this model has not been adopted either in rural or urban catchment areas'. No evidence is quoted for this sweeping statement.

Admittedly, in our fast moving National Health Service it is difficult to keep track of changes. In 1997 we investigated the work of old age psychiatrists. ${ }^{3}$ Every day of the week community clinics were reported by $20 \%$ or more of respondents (the corresponding figures for hospital out-patient clinics ranged between 17 and $28 \%$ ). Additional community activity was undertaken as domiciliary visits and new home visits. Domiciliary visits are welldefined: they incur additional payment and occur at the request of the general practitioner, normally in his or her company, to advise on diagnosis or treatment, where the patient cannot attend hospital on medical grounds. Home visits can involve follow-up or new assessments and are undertaken without additional remuneration as part of the doctor's working day.

We later reported a more in-depth analysis which found that community activity was greater among consultants working with colleagues in comparison with those who worked alone. ${ }^{4}$

Since then, Richardson \& Orrell have reported that home assessments are popular with patients, carers and professionals, going on to argue that they also provide more information. ${ }^{5}$ The College Faculty of Old Age Psychiatry seems to think community clinics are normal practice. ${ }^{6}$

In all the services we have worked in, home visits carried out during community clinics have been the norm - but then neither of us has worked in Yorkshire. Visits are efficient and cost-effective, with non-attendance rates consistently lower than $10 \%$ in our services, as well as providing the continuity of follow-up desired by patients, carers and colleagues in primary care and social services, and in line with the National Dementia Strategy. ${ }^{7}$ It is important that Negi et al set the record straight: in many good services for older people home visits are the reality.

1 Negi R, SeymourJ, Flemons C, Impey M, Thomas N, Witrylak R. Psychiatric out-patient clinics for older adults: highly regarded by users and carers, but irreplaceable? Psychiatr Bull 2009; 33: 127-9.

2 Benbow SM. The community clinic - its advantages and disadvantages. Int J Geriatr Psychiatry1990; 5: 119-21.

3 Jolley DJ, Benbow SM. The everyday work of geriatric psychiatrists. Int J Geriatr Psychiatry 1997; 12: 109-13.

4 Benbow SM, Jolley DJ. Gender, isolation, work patterns and stress amongst old age psychiatrists. Int J Geriatr Psychiatry 1999; 14: 719-25.

5 Richardson B, Orrell M. Home assessments in old age psychiatry. Advan PsychiatrTreat 2002; 8 : $59-65$

6 Faculty of Old Age Psychiatry. Raising the Standard. Specialist Services for Older People with Mental Illness. Royal College of Psychiatrists, 2006 (http://www.rcpsych.ac.uk/PDF/ RaisingtheStandardOAPwebsite.pdf).

7 Department of Health. Living Well with Dementia: A National Dementia Strategy. Department of Health, 2009.

Susan Mary Benbow Professor of Menta Health and Ageing, Centre for Ageing and Mental Health, Staffordshire University, Blackheath Lane, Stafford ST18 OAD, email: drsmbenbow@aol.com, David Jolley Consultant Psychiatrist, Pennine Care NHS Foundation Trust, and Honorary Reader, Manchester University Personal Social Services Research Unit

doi: $10.1192 / p b .33 .8 .315$

\section{Therapists' competence - maintenance matters too}

Davidson \& Scott left us in no doubt that therapist competencies matter in the delivery of psychological therapies. ${ }^{1}$ As a concept there has always been a degree of 'face validity' to this assertion, but it is the attention they devote to maintaining competence that is perhaps of most significance - and most concern - within psychiatry. In 2005, the Psychiatric Bulletin published the results of a survey of psychiatrists who had received training to diploma level at one of Scotland's recognised cognitive-behavioural therapy (CBT) courses. ${ }^{2}$ The results clearly established that access to personal supervision and for some also opportunities in continuing professional development were poor. Nevertheless, there was optimism that with the advent of job planning, consultant psychiatrists could spell out and negotiate for the time needed to undertake this, so as to ensure that these specific skills are not wasted. Indeed, Whitfield concludes that 'planners should think carefully about how to harness and hold on to psychiatrists with these (CBT) skills if future diversity in psychological skills training is to be assured'. ${ }^{2}$

For CBT at least, the assessment of the competencies required to deliver effective therapy has been aided by the publication of a self-assessment tool by the British Association for Behavioural and Cognitive Psychotherapies (www.babcp.com/ members-/a-self-assessment-tool-of-cbtcompetences-/), in response to the 2007 Department of Health publication, ${ }^{3}$ and the Royal College of Psychiatrists has outlined the competencies required for training in psychotherapy in general. Not knowing why, how or what to do is no longer an issue.

Unfortunately, in 2009 consultants face increasing pressure from employers to replace supporting professional activity time with direct clinical care time, the assumption being that this will bring better value for money for the National Health Service. Jobs with as few as one supporting professional activity are being advertised which in our view is inadequate to allow consultant psychiatrists to be involved in teaching and training as well as maintaining their own continuing professional development. This would be regarded as completely unacceptable by others involved in delivering psychological therapies, for example clinical psychologists.

It seems highly likely that increased direct clinical care time by consultants will come at the expense of robust supervision arrangements for them and for the supervision that they can supply. This makes it likely that improved access to psychological therapies, at least as delivered by psychiatrists, will not bring 